
cultural y científica entre Perú y Francia

\title{
Fotógrafos franceses en el Perú del siglo XIX
}

Les photographes français au Pérou au XIXème siècle

French photographers in Peru's, nineteen century

\section{Herman Schwarz}

\section{OpenEdition \\ Journals}

Edición electrónica

URL: http://journals.openedition.org/bifea/4469

DOI: $10.4000 /$ bifea.4469

ISSN: 2076-5827

Editor

Institut Français d'Études Andines

Edición impresa

Fecha de publicación: 8 mayo 2007

Paginación: 39-49

ISSN: 0303-7495

Referencia electrónica

Herman Schwarz, "Fotógrafos franceses en el Perú del siglo XIX », Bulletin de l'Institut français d'études andines [En línea], 36 (1) | 2007, Publicado el 08 mayo 2007, consultado el 01 diciembre 2020. URL : http://journals.openedition.org/bifea/4469; DOI : https://doi.org/10.4000/bifea.4469

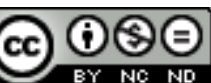

Les contenus du Bulletin de l'Institut français d'études andines sont mis à disposition selon les termes de la licence Creative Commons Attribution - Pas d'Utilisation Commerciale - Pas de Modification 4.0 International. 


\title{
Fotógrafos franceses en el Perú del siglo XIX
}

\author{
Herman Schwarz
}

\begin{abstract}
Resumen
En los albores de la lucha por la independencia peruana del dominio español (1821), se inventa la fotografía en Francia (1839), cuya patente es comprada por el gobierno y compartida con el mundo (menos Inglaterra). El Perú vive la prosperidad económica por la explotación del guano que convierte a Lima en una plaza interesante para este nuevo negocio.

La llegada al puerto del Callao del primer daguerrotipo se dio en 1842. A partir de entonces se instalarían los primeros fotógrafos franceses (1844-1855): Philogone Daviette, Furnier, A. de Lattre, Amic Gazan y Émile Garreaud. Este último abandona la técnica del daguerrotipo y propagandiza el nuevo método del colodión húmedo (negativo de vidrio) que permite, a diferencia de la copia única del primero, la múltiple reproducción de la imagen.

En 1860, el estudio Nadar de París está de moda en Francia, mientras en Lima abre sus puertas el lujoso estudio de su corresponsal Eugène Maunoury, quien hace popular la tarjeta de visita. En 1865, su antiguo operario Eugène Courret le compra sus activos y se convierte en el estudio más importante de la segunda mitad del siglo XIX hasta su cierre definitivo en 1935.

Sus archivos contienen parte de la historia gráfica del Perú: la definitiva expulsión de los españoles de las costas peruanas (batalla del 2 de mayo, 1866), la explotación del guano en las islas Chincha, la guerra con Chile y los personajes más importantes de su época pasaron por el famoso estudio limeño. Parte del Archivo Courret (55 000 placas) fue adquirido por la Biblioteca Nacional del Perú en la década de 1980.
\end{abstract}

Palabras clave: historia de la fotografía, daguerrotipo, colodión húmedo, guano, guerra con Chile, Courret, Lima

\section{Les photographes français au Pérou au XIXème siècle}

\section{Résumé}

C'est à l'aube de l'indépendance du Pérou de la domination espagnole (1821) que la photographie est inventé en France (1839). Sa patente est achetée et partagée avec le monde (sauf l'Angleterre) par le 
gouvernement français. Le Pérou est en pleine prospérité économique due à l'exploitation du guano, ce qui fait de Lima un endroit intéressant pour ce nouveau marché.

C'est en 1842 que parvient le premier daguerréotype au port de Callao. II marque l'installation des premiers photographes français (1844-1855) : Philogone Daviette, Furnier, A. de Lattre, Amic Gazan et Émile Garreaud. Ce dernier abandonna la technique du daguerréotype et difusa la nouvelle méthode du collodion humide (négatif sur verre) qui permet, à la différence de la copie unique de la première, la reproduction de l'image à l'infini.

En 1860 le studio Nadar de Paris était à la mode en France, tandis qu'à Lima ouvre ses portes le luxueux studio de son correspondant Eugène Maunoury qui rend populaire la carte de visite. En 1865 , son ancien ouvrier, Eugène Courret lui achète son capital et transforme le studio en celui qui sera le plus important de la seconde moitié du XIXe siècle jusqu'à sa fermeture définitive en 1935.

Ses archives contiennent une partie de l'histoire graphique du Pérou: I'expultion définitive des Espagnols des côtes péruviennes (bataille du 2 mai 1866), l'exploitation du guano des îles Chincha, la guerre avec le Chili et les personnages les plus importants de l'époque passèrent par le fameux studio liménien. Au cours des années 1980 la Bibliothèque Nationale du Pérou acquiert une partie de l'Archive Courret (55 000 plaques).

Mots clés : histoire de la photographie, daguerréotype, collodion humide, guano, guerre avec le Chili, Courret, Lima

\title{
French photographers in Peru's, nineteen century
}

\begin{abstract}
Shortly after the war of the Peruvian independence from the Spanish rule (1821), photography was invented in France (1839). The French government bought the rights of the new discovery to share it with the world (with the exception of England).At that time Peru was experiencing economic prosperity due to the exploitation of huge amounts of guano, a natural resource, and Limabecame an interesting place for the new trade.

The first daguerreotype arrived at the port of Callao in 1842, only three years after its discovery. Afterwards French photographers arrived such as Philogone Daviette, Furnier, A de Lattre, Amic Gazan and Emile Garreaud. This last indivdidual started revolutionary technique of the wet collodion, which provided a negative image in a glass plate that allowed multiple reproduction of the image, instead of the unique copy provided by the daguerreotype.

In 1860, the French photographer Nadar was very famous in Paris, while in Lima his correspondent Eugene Maunoury opened a fancy studio that made the carte de visite very popular. A few years later, his employee Eugene Courret and his brother bought his share of the business and made of the Courret Brother's Studio the most important one of the history of Peruvian photography until it finally closed in 1935. The Courret archives contain the most important graphic testimony of Peruvian events during the second half of the nineteen and the first three decades of the twentieth century. Courret. Photographed the war with Spain in 1866, the War of the Pacific with Chile and portraits of the most important people of his time. The 55000 glass negative plates of the Courret Studio were acquired by the Biblioteca Nacional of Peru in the 1980.
\end{abstract}

Key words: history of photography, daguerreotype, wet collodion, guano, war against Chili, Courret, Lima 


\section{PRIMEROS ESTUDIOS SOBRE LA HISTORIA DE LA FOTOGRAFÍA PERUANA}

Fue solamente en los años 1970 que se iniciaron estudios sobre la fotografía peruana. El pionero fue Keith McElroy, de la Universidad de Nuevo México, quien investigó a los primeros fotógrafos que trabajaron en el Perú y, finalmente, por qué Lima fue una plaza importante para el auge de los grandes estudios fotográficos a mediados del siglo XIX. La tesis con la que McElroy obtuvo su grado de Ph.D. se titula: La Historia de la Fotografía en el Perú en el siglo XIX: 1839-1876. El documentado trabajo de McElroy fue publicado en inglés en 1977. Años después, Liliana Peñaherrera obtendría el grado de Bachiller en Historia con la tesis: Un documento histórico: la fotografía en el Perú (1895-1919) (Peñaherrera, 1983).

Un notable esfuerzo que hay que destacar es el del Museo de Arte de Lima, que con el apoyo de la Fundación Telefónica montó en 2001 la exposición más importante hecha en el país sobre la historia de la fotografía peruana, labor redondeada con la publicación del libro La recuperación de la memoria, 1842-1942. Esta muestra, en realidad, tuvo dos partes: en la sala de exposiciones de la Telefónica se expuso «Martín Chambi y sus contemporáneos» y en el Museo de Arte de Lima «El primer siglo de la fotografía. Perú 1842-1942» (Majluf \& Wuffarden, 2001).

A esta sucinta relación de trabajos que han aportado al develamiento de la historia gráfica peruana debemos añadir el libro de Guillermo Thorndike, publicado en 1979, Autorretrato. Perú 18501900, con imágenes inéditas, hasta ese momento, del Archivo Courret (Thorndike, 1979).

Esta pequeña introducción es un reconocimiento a estos historiadores y escritores por su aporte a las investigaciones sobre la historia de la fotografía peruana. Nos podemos imaginar las enormes dificultades que deben haber pasado para obtener toda la información lograda, donde a la falta de datos en los archivos encontrados, sin testimonios directos de los mismos fotógrafos estudiados (documentos como cartas o diarios), se suma la inexistencia de entrevistas a estos mismos en los medios de prensa, y las condiciones climáticas de Lima, cuya humedad fácilmente llega al $100 \%$, y que ha sido la causante de la destrucción de gran parte de las imágenes que conforman la historia gráfica peruana.

Pero hay que decir algo: el peor mal que nos aqueja es la desidia, esa desidia que todo lo destruye. La misma desidia que llevó a los descendientes de la familia del extraordinario fotógrafo Sebastián Rodríguez a botar sus cajas con las placas negativas de vidrio al basural de la pampa de Morococha, donde Fran Antmann se enteró que un grupo de chiquillos se había dedicado a reventarlos a pedradas. La misma desidia que llevó a la familia del fotógrafo Cesáreo Mosquera de Iquitos a tratar de entregar infructuosamente a la Municipalidad de esta ciudad ocho cajones de madera con los negativos de vidrio de varios fotógrafos entre los que se encontraban los de Victoriano Gil, Almenara y Lira entre otros, porque no sabían que hacer con ellos. Cuando don Joaquín García, sacerdote español y director del CETA, acudió donde esta familia, allá por el año 1868, le dijeron que, como nadie quería los negativos, los tiraron al río. Y esto no fue una metáfora.

Por lo tanto, estos investigadores debieron superar las frustraciones del maltrato cotidiano a la cultura expresada en estos actos y rebuscar en los archivos de las bibliotecas más importantes, en las colecciones privadas y publicaciones de época, para ir rescatando y armando, como un gran rompecabezas, esta historia del olvido. De los primeros daguerrotipistas no ha quedado obra tangible, porque las técnicas primitivas, acompañadas de la inclemencia del clima limeño, han borrado - literalmente - sus imágenes de la historia. Y de los que han sobrevivido, pocos daguerrotipos llevan el sello del autor.

El siguiente texto se ha elaborado en base a las investigaciones que he mencionado aquí, donde se destaca la participación de los fotógrafos franceses. Omitiremos, por esa razón, a los otros fotógrafos extranjeros y nacionales de la época, sin que por ello se desmerezca su aporte a nuestra historia gráfica. 


\section{LA ERA DAGUERREANA (1839-1859)}

\section{1. París, 1939}

Este fue un año clave en la historia de la Fotografía, porque ese mismísimo año Henry Fox Talbot en Inglaterra y Louis Jacques Mandé Daguerre, en Francia, presentaron sus descubrimientos fotográficos en sus respectivos países. Fox Talbot descubrió el proceso negativo positivo y la fotografía sobre papel. Con el método de Daguerre se conseguía una copia única sobre una plancha de metal. Siendo justos, debemos admitir que, a pesar de los esfuerzos y méritos de otros pioneros, el que demostró un mayor grado de perfección en su técnica fue el daguerrotipo.

Ante estas circunstancias, las Academias de Ciencias y Bellas Artes se reunieron, en acto oficial, el 19 de agosto de 1839 en el Instituto de Francia, y fue el científico François Arago quien proclamó al mundo el nacimiento de la fotografía. El hecho de que el Estado francés le haya comprado a Daguerre su invento hizo posible que, al día siguiente del anuncio oficial en París, el mundo entero se fuera enterando al detalle de los minuciosos procedimientos del daguerrotipo y se lanzasen a tratar de fijar en estas brillantes planchas de metal todo lo que fuese posible de ser fotografiado. Cabe resaltar que el único país excluido de esta donación francesa fue Inglaterra, donde Daguerre había patentado su invento apenas cinco días antes de su develamiento (Frizot, 1976: 26).

\section{2. Lima, 1840}

«Creo que la circunstancia que reanimó fundamentalmente el interés europeo por el Perú en la segunda mitad del siglo XIX fue el auge de la explotación del guano. Los franceses fueron los primeros en conocer las ventajas del nuevo producto divulgando su importancia para la economía agrícola de la época. El nombre del Perú volvió a ser sinónimo de riqueza, adquiriendo el prestigio equívoco que en su hora hubieron de gozar California y las minas de Sudáfrica». (Macera, 1976: 136)

Entre ellos se encontraba, según el estudioso norteamericano Keith McElroy (1977: 428), el primer miembro de la familia Courret, don Francisco Courret, veterano de la batalla de Waterloo, quien establece ese mismo año, en la ciudad de Lima, un negocio de venta de productos y exquisiteces importadas de Francia.

Conocido como «La mampara de bronce», este negocio también funcionó como agencia de bienes importados, vinculada a algunas compañías navieras francesas. En una compilación de varias listas de aduana podemos encontrar los siguientes productos: vino Burdeos, coñac, papel pintado, figuras de cartón para modistas, lunas de espejo, plumas, bombas de cristal para lámparas, candeleros, cerveza, lamparitas para velar, relojes de sobre mesa, casimir labrado, terciopelo, botones de seda y cuerno, cocos negros y blancos para forros, flores de mano, pañuelones de casinete, santos de barro con sus cilindros de cristal, agua de lavanda, chicha de uva, cebada, harina greda o tiza, varias frioleras de música, almas de silla para montar, arneses para birloche, calienta pies, cubiertos de fierro, libros impresos, semillas de flores, sarga corchetes, piedra de enlozar, bastones, fusilitos para niños y una variedad de artículos más (McElroy, 1977: 461).

Según se anunció en el diario El Comercio en 1842:

«Hasta ahora, no se han hecho ensayos de este descubrimiento portentoso en esta capital o si se han hecho, no habían salido con el fin propuesto. Pero el señor Maximiliano Danti, recién llegado de Francia con un daguerrotipo que sabe manejar perfectamente, ha hecho ya numerosas pruebas, $y$ todas le han salido muy bien».

Esta nota salió publicada el 8 de julio de ese año y tuvo como título «Daguerrotipo» (El Comercio, 8 de julio de 1842: 4). 
McElroy nos hace notar la importancia de la fecha inaugural del establecimiento de Danti a una cuadra de la Plaza de Armas. Resulta que el primer estudio en el mundo se abre en la ciudad de Nueva York, en marzo de 1840; el primero en Europa (en Londres), en marzo de 1841, el mismo año que en París. Sin embargo, en Berlín recién se abre un estudio en agosto del 1842, un mes después del estudio de Danti. Por lo tanto, sostiene McElroy, no existió ningún retraso ni cultural ni comercial frente a Europa en cuanto a lo que a fotografía se refiere.

El segundo daguerrotipista llegado a Lima fue el francés Philogone Daviette, quien estuvo activo entre 1844 y 1846 . Este año le tomó la posta otro francés: Furnier, quien se presentó sólo con el apellido y como el «daguereotipógrafo de París» (sic). Su estudio se encontraba en la Plazuela de San Agustín y en sus avisos publicitarios destacaba que incluso hacía fotografía post-mortem «... como es costumbre en Europa hoy en día» (El Comercio, 27 de marzo de 1846: 4).

Otro figurante de esta historia, de origen francés, fue A. de Lattre, quien se presentó primero como pintor de miniaturas y luego como daguerrotipista, quien tuvo una corta estadía en Lima, entre 1845 y 1846 . Aseguraba que sus imágenes demandaban solo quince segundos de toma debido a que usaba un novísimo y mejorado método que practicaba.

En 1855, Amic Gazan y su familia llegaron al Callao, procedente de Francia, acompañado de Emilio Garreaud. Al año siguiente, en febrero, estaban inaugurando el estudio «Fotografía de París» (McElroy, 1977: 407). La palabra fotografía era nueva y se usó para diferenciarse de los que hacían daguerrotipos y ambrotipos. Tras la partida de Gazan, el estudio se convertiría en 1858 en solo E. Garreaud y Cia. En setiembre de ese año, Garreaud publicaba en un aviso en EI Comercio lo siguiente:

«Ya en las ciudades de Europa nadie piensa hoy más en hacerse retratos al Daguerrotipo o Ambrotipo por ser estos perecederos y tan duros de perfil, y sobre todo por ese deslumbre desagradable a la vista con que salen siempre los vidrios y planchas cuando se emplean estos antiguos y obsoletos métodos».

En julio de 1859 arremetía con otro del mismo calibre: «¿Quién pensaría todavía en dejarse retratar en daguerrotipo? Estamos seguros que nadie...», decía Garreaud (El Comercio, 7 de junio de 1859: 1).

Las sucesivas ampliaciones de los estudios, así como las compras de equipos, eran parte de la competencia de los estudios, la que llegó a su punto más candente cuando Garreaud abre un nuevo y tal vez el más grande y lujoso estudio de Lima. Los avisos publicados por Garreaud, en 1859, alcanzaron niveles récord de espacio en su época y poco antes de la inauguración del nuevo local llegó a publicar hasta tres avisos en la misma edición. Bajo circunstancias aún no esclarecidas, Garreaud abandona el estudio y al año siguiente se estaba estableciendo en Chile, donde llega a abrir sucursales en Valparaíso, Santiago, Copiapó, La Serena, Talca y Concepción (Majluf \& Wuffarden, 2001: 62).

\section{LA ERA DE LA CARTE DE VISITE}

\section{1. París, 1854}

Quedaron atrás los años del auge del daguerrotipo y de las largas exposiciones bajo el sol del mediodía. Es la era del colodión, el negativo de vidrio y por ende de la reproducción ilimitada de copias. En París, Nadar estaba de moda. En 1854 abrió su célebre estudio, el que pronto se convertiría no solo en el más distinguido, sino en el lugar de reunión de intelectuales y artistas. De hecho, fue en este local donde en 1874 se celebró la primera exposición de los impresionistas, rechazados por el Salón oficial. Entre sus retratos más conocidos figuran los de Baudelaire, Corot, Daumier, Doré, Delacroix, Julio Verne, Víctor Hugo, Manet, Sarah Bernhardt, entre muchos otros. 


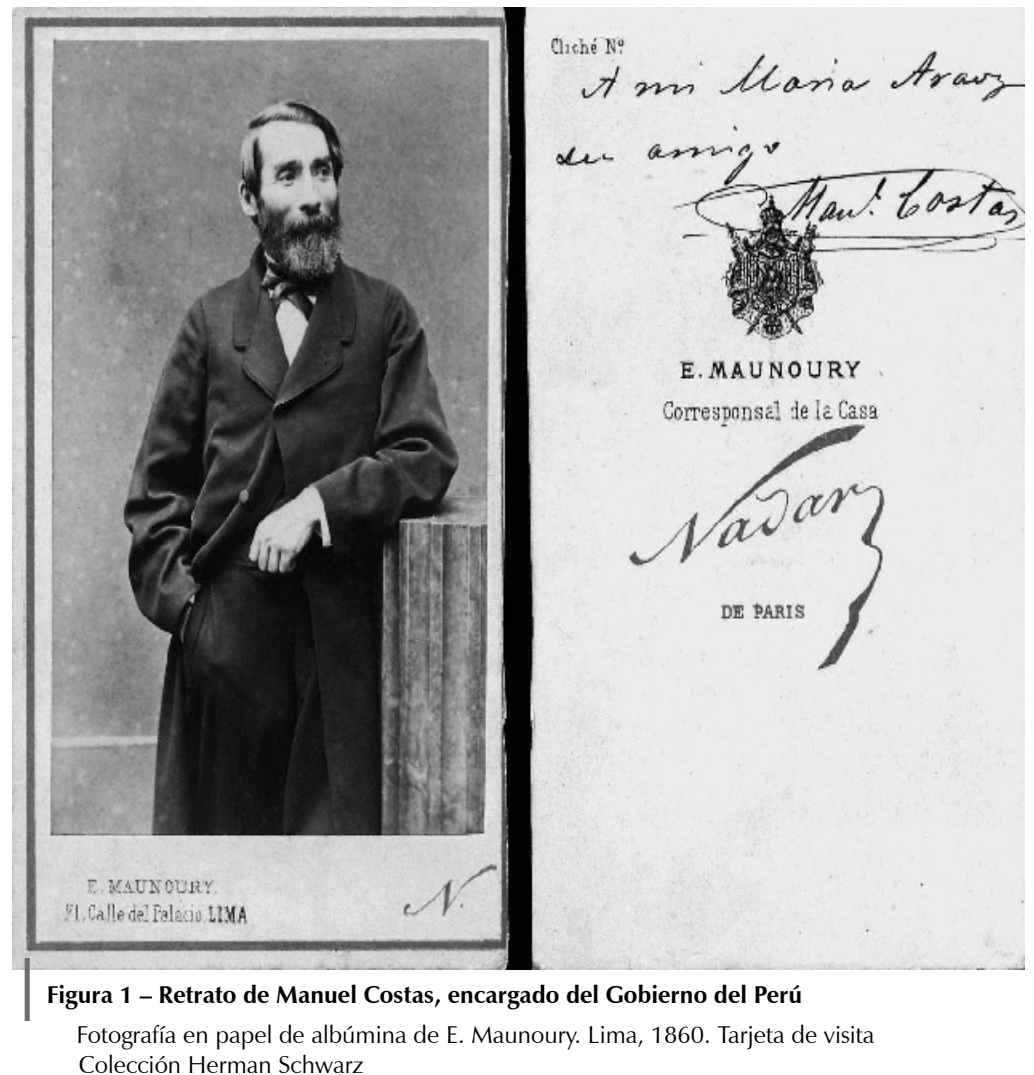

El fotógrafo Disderí, también en París, patenta el formato conocido como carte de visite o tarjeta de visita, cuyas dimensiones eran $6 \times 9 \mathrm{~cm}$. Sin embargo, este formato no se hace popular hasta que Napoleón III posa para Disderí y éste lo pone a la venta. El éxito fue inmediato y espectacular, desde ese momento se puso de moda en el mundo entero. Esta moda llegó a Lima en 1859 con el fotógrafo francés Félix Carbillet.

A partir de entonces todos se hacían sus tarjetas retrato o de visita para repartirlas entre sus conocidos, como hoy se hace con las tarjetas de presentación. Para esto se fabricaron los álbumes, donde la gente empezó a coleccionarlas. Pero no solo iban al álbum las tarjetas de los familiares y amigos, sino también de paisajes de la ciudad y de lugares lejanos y exóticos, también las de los presidentes, de artistas famosos, y hasta las llamadas de tipos y costumbres.

\section{2. Lima, 1862}

En enero del 1862 (McElroy, 2000: 122) abre sus puertas la Sociedad Fotográfica Maunoury y Cia., en la calle del Palacio. Los arreglos de los grandes salones del nuevo establecimiento corrieron a cargo del arquitecto francés Pedro Cluseau. Para tal fin trajeron lujosos muebles de Europa, sedas y terciopelos para las cortinas, y hasta un piano, objeto raro por esos años, y que fueron anunciados como parte de los decorados de los ambientes del nuevo gran salón fotográfico. Los anuncios en los periódicos se publicaban a diario y hasta en las esquinas más concurridas de la ciudad fueron pegados afiches que anunciaban la inauguración del estudio. 


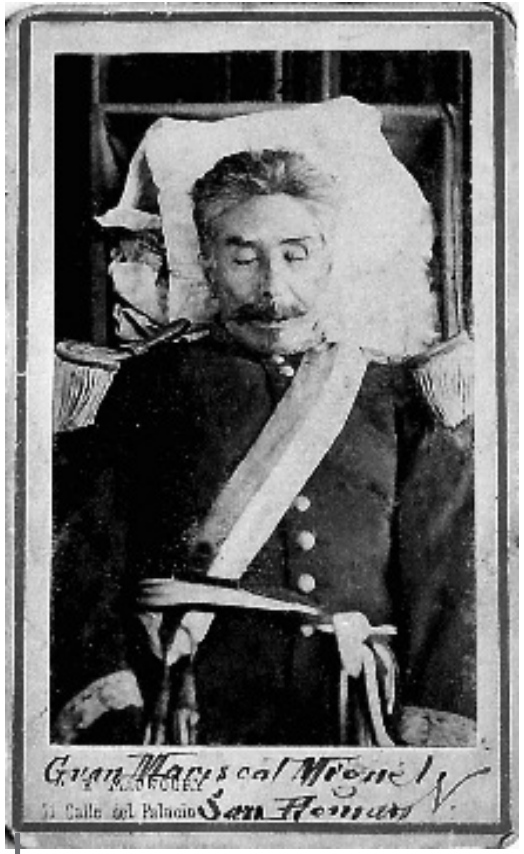

Figura 2 - Retrato post-mortem del presidente del Perú, Mariscal Miguel de San Román

Fotografía en papel de albúmina de Eugène Maunoury, Lima, 1863. Tarjeta de visita (6,5 x 10,5 cm). Colección Biblioteca Nacional del Perú
A partir de diciembre de 1862 Eugène Maunoury se publicita como corresponsal de la famosa Casa Nadar de París, hecho que destaca en la prensa, llegando inclusive a hacer pública, en el Mercurio de Lima, una carta del propio Nadar.

«Tengo el honor de avisar al respetable público de esta capital, que sólo en Lima, el Sr. Maunoury, fotógrafo, 71- Calle del Palacio -71, es el único poseedor de mis nuevos procedimientos fotográficos, premiados en París $y$ en Londres.

Nadar. 35 Boulevard des Capucines, Paris». (El Comercio, 4 de mayo de 1863: Última página)

El estudio fue un éxito desde el primer momento y pronto tendría dos sucursales: uno en la calle Constitución 36 del Callao y otra en Plateros de San Pedro $\mathrm{n}^{\circ}$ 8. Eugène Courret llegaría de Francia, poco después para trabajar como operario del estudio de su compatriota Eugène Maunoury (Laurel, 1861). En el Anuario 1862 aparece un aviso de media página de La Mampara de Bronce, donde se menciona el nombre de A. Courret como propietario; suponemos que es Aquiles, el hermano de Eugène.

Para febrero de 1863 los hermanos Courret ya estaban desembarcando equipos para reemplazar el antiguo negocio familiar con su propio estudio fotográfico. Los cambios en el local fueron radicales, llegando a construir una entrada por el transitado pasaje Petateros, hoy Pasaje Olaya. Para el mes de marzo los Courret estaban inaugurando la casa fotográfica a la que pusieron por nombre «Fotografía Central». Todo parece indicar que la separación con Maunoury fue amistosa.

Desgraciadamente, no existen datos biográficos de Eugène Maunoury. Se sabe que vino de Francia y que antes de llegar al Perú estuvo activo en Chile, donde se asoció con el fotógrafo Imbert y recorrió el país sureño reuniendo una colección de vistas de paisajes, incluyendo escenas del gran incendio de Valparaíso de 1858.

Maunoury trabajó como corresponsal de Le Monde Illustré de París desde 1863, para quienes había despachado algunas notas de actualidad en las que tocaba temas como: los funerales de Don Miguel de San Román ( $n^{\circ} 320$ : 30/5/1863); la hoja de coca ( $n^{\circ} 358: 20 / 2 / 1864$ ); el congreso internacional de ministros plenipotenciarios de las repúblicas de América del Sur $\left(n^{\circ}\right.$ 405: 14/1/1865: 20); los tipos indígenas del Perú ( $n^{\circ}$ 434: 5/8/1865: 84); y una vista general de la Villa de Valparaíso ( $\mathrm{n}^{\circ}$ 453: 16/12/1865: 388). Esta interesante relación de colaboraciones figura en la página web del Instituto Católico de París, en su sección fototeca, probablemente porque estos envíos fueron fotografías que luego publicaran como grabados. Sería interesante revisar los ejemplares originales de esta publicación.

Hubo un grave incidente ocasionado por un envío de Maunoury que no está mencionado en esta relación. Tal vez se deba al hecho de que esa vez Maunoury envió, junto a un texto, un dibujo para ilustrarlo. En él se detallaba la agresión que sufriera una delegación de marinos españoles en el puerto del Callao en 1865, los que tuvieron que refugiarse en la Legación francesa. En el grabado, basado en su dibujo, los españoles y los franceses aparecían tratando de salvarse de ser linchados por una turba de peruanos. Hay que tener en cuenta que los españoles habían tomado las islas guaneras de Chincha en abril del año anterior y el ambiente estaba caldeado. Las críticas, entre las que estaban las de El Comercio y El Mercurio, trataron duramente a Maunoury, hecho que precipitó su salida en mayo del mismo año. 
De Maunoury se conocen hasta dos tarjetas de visita con el logo parisino, las que fueron ofrecidas a través una página web de remates. Aunque son imágenes relativamente pequeñas, se ven los logotipos que probarían que continuó su trabajo en Francia.

\section{EL DESPEGUE DE LOS HERMANOS COURRET}

Tan grande habría sido el éxito de los hermanos Courret por el auge de las tarjetas de visita que para 1865 ya le habían comprado a Maunoury el íntegro de sus estudios, con sus equipos y archivos incluidos: el de la calle Palacio, considerado el más lujoso de la ciudad, el del Callao en la calle Constitución, y un tercer local en Plateros de San Pedro. Inmediatamente, la sucursal de la calle Palacio puso en sus tarjetas de visita «Courret Hermanos sucesores de E. Maunoury». El monograma de la Casa Nadar de París recién apareció en las tarjetas de visita de los hermanos Courret desde finales de 1865 hasta el año 1868. Esta corresponsalía finaliza, según McElroy, debido a razones estrictamente económicas.

El estudio usó el escudo de armas francés que antes usó Maunoury hasta 1868, cuando se cambió por el escudo peruano. En 1873 desaparece el logotipo de Courret Hermanos y aparece sólo E. Courret. Este cambio sugiere el retiro y posible regreso a Francia de su hermano Aquiles, quien se desempeñaba como el administrador del estudio.

Durante el combate del 2 de mayo de 1866, que puso término a las pretensiones de España de retomar el control de su antigua colonia, Courret hizo las célebres fotografías del cañón del pueblo y otra obra que luego fue una pintura de Crapelet — también francés- hecha al óleo sobre una fotografía tomada por Courret. Con este trabajo que llevó a la primera Exposición Industrial de Lima, ganó la medalla de plata. Más tarde, en la Exposición de 1872, ganaría la medalla de Oro.

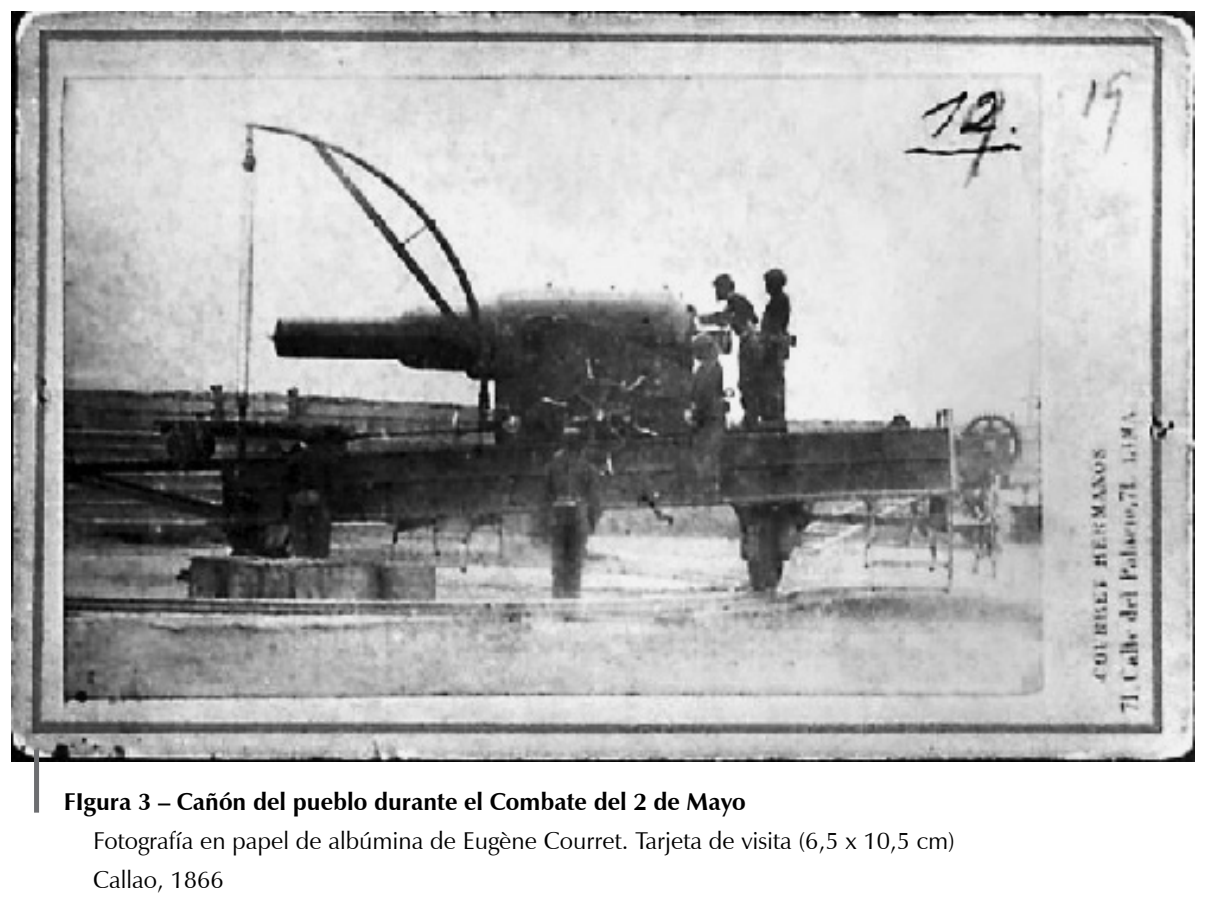


Los datos en el reverso de las fotografías en todos sus formatos, así como los cambios de logotipos del estudio, son de gran ayuda para fechar tentativamente muchas de estas imágenes que carecen de información.

En 1875, al empresario Enrique Meiggs le fue encargada la construcción del ferrocarril central y contrató a los fotógrafos Villroy Richardson (norteamericano) y Eugène Courret para documentar la obra.

Otras imágenes impactantes de Courret fueron las que tomó sobre la destrucción del balneario de Chorrillos durante la Guerra del Pacífico. Los años de la ocupación chilena de Lima fueron también graficados por Eugène Courret, con muchas fotografías hechas en el estudio de oficiales y de la soldadesca chilena en diferentes posturas.

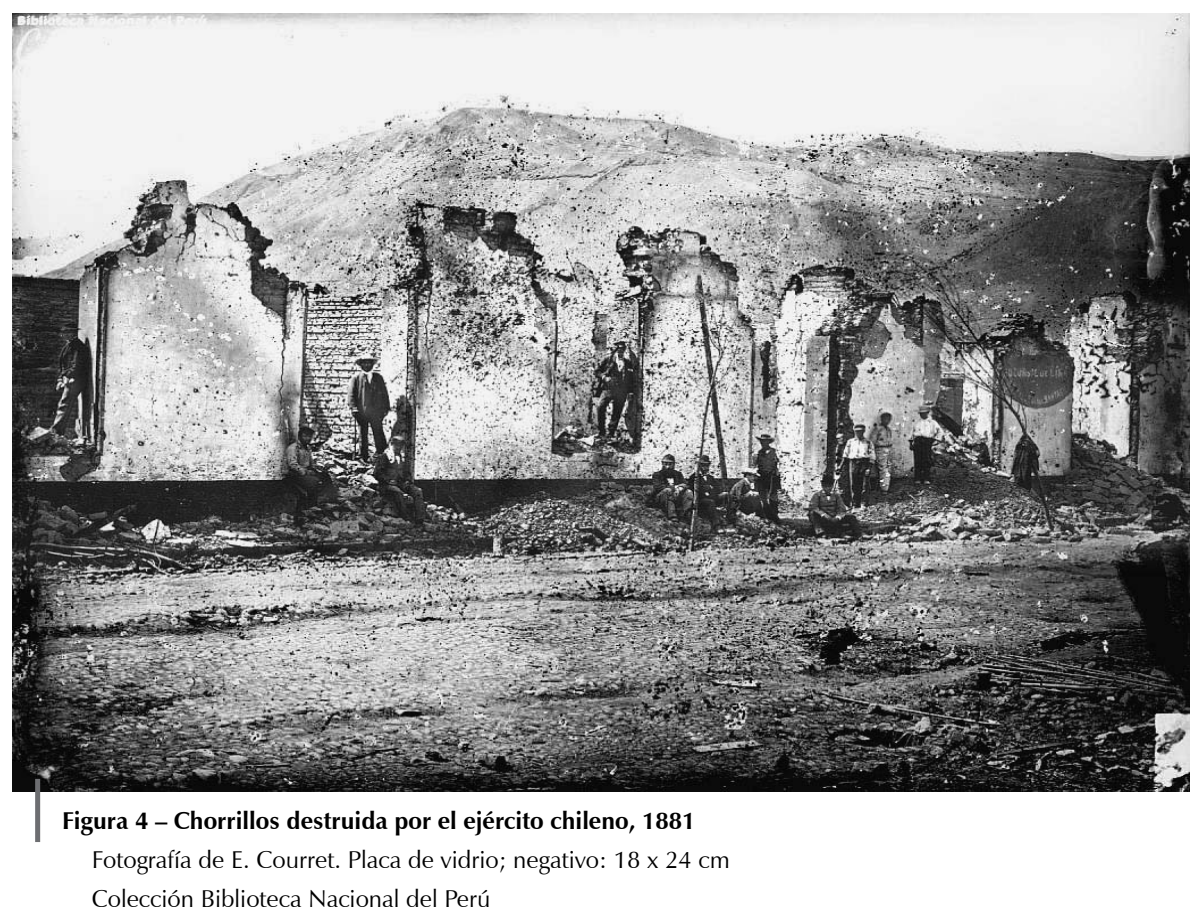

A partir del año 1887, el nombre del estudio cambia a Courret y Cia. y los locales se reducen a uno, el que estaba en la calle Mercaderes (hoy Jirón de la Unión, tercera cuadra). Este cambio podría suponer la asociación con Adolfo Dubreuil (hijo de francés), aunque McElroy supone que el cambio de nombre supone su retiro definitivo del negocio, por lo menos en Lima.

Lo cierto es que en la última década del siglo, posiblemente en 1892, los Courret regresaron a Francia donde, al igual que Maunoury, siguieron trabajando como fotógrafos. En una tarjeta de visita del archivo de la Biblioteca Nacional se encuentra una en la que se lee al reverso: «Photographie Courret/19 Cité du Retiro/París», que contribuye a esta hipótesis.

Sin embargo, ha aparecido hace poco un retrato del tamaño llamado imperial que dice en el anverso: «Courret, Paris 10 Boulevard Montmartre», y al reverso se agrega otro dato:

«Sucesores de P. Mockel \& Cie».

Lo anterior habla de la gran actividad que tuvo Courret a su regreso a París, de donde había salido a la edad aproximada de 20 años. El sucesor de su estudio fue un descendiente de 


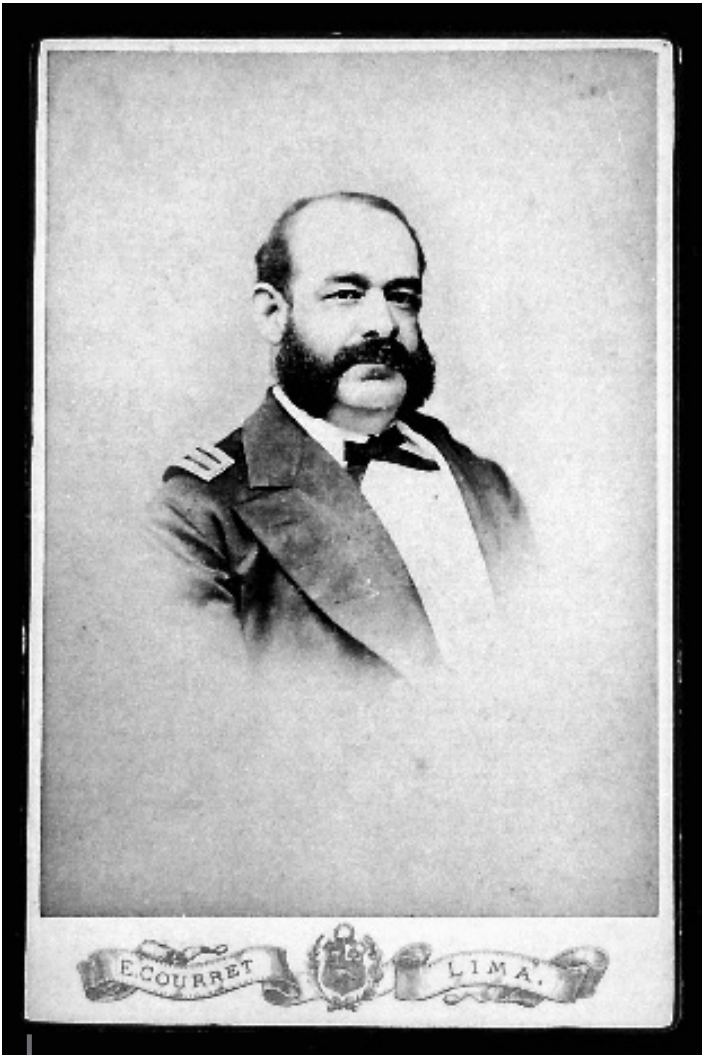

Figura 5 - Almirante Don Miguel Grau

Fotografía de E. Courret. Presentación Gabinete 16 x11 cms Lima, ca 1880

Colección Museo Naval del Perú francés llamado Adolfo Dubreuil, quien estuvo al frente de la compañía hasta que lo sucede su hijo René, en la segunda década del nuevo siglo y luego su nieto Adolfo. En 1929 el estudio contaba con 157800 negativos y ya era conocido como Fotografía Dubreuil. El Estudio Courret cierra definitivamente, por quiebra, en 1935, indemnizando a sus trabajadores con sus bienes patrimoniales: equipos y placas de vidrio.

\section{EL ARCHIVO COURRET}

El Estudio Courret se mantuvo abierto al público más selecto de Lima durante cerca de 70 años, de los cuales aproximadamente 29 estuvieron bajo la dirección de la familia Courret. Los restantes 42 años estuvo bajo el manejo de Dubreuil y su descendencia. Sin embargo, es Courret quien se lleva la gloria y esto no es gratuito. Fue quien estableció el estudio y creó el enorme prestigio gracias a su trato y talento. Este prestigio fue reconocido evidentemente por Dubreuil, pues conservó el nombre como logo hasta la década de 1920.

Además, Eugène Courret fue también fundador de una escuela por donde pasaron grandes fotógrafos, empezando por el mismo Adolfo Dubreuil, Diego Goyzueta, Elías del Águila y Luis Ugarte. Todos ellos, y posiblemente otros más, también formaron a otras generaciones de fotógrafos.

El editor Don Juan Mejía Baca, siendo Director de la Biblioteca Nacional del Perú, fue quien logró que gran parte del archivo Courret pasara a formar parte del patrimonio de la Biblioteca el año 1987, donde aún se conserva, pese a los males endémicos ya mencionados. Este archivo proviene de los herederos de Carlos Renjifo Farromeque, quien fue indemnizado con una parte de las placas de vidrio por el último de los Dubreuil. El resto, se repartió entre los otros trabajadores.

El Instituto Fotográfico Eugène Courret del jirón Azángaro adquirió de la familia de Juan Castañeda, otro ex empleado, quien habría tenido en su posesión además el archivo del fotógrafo Elías del Águila, un total aproximado de 30000 negativos de vidrio.

Por ahora, solo queda mantener la esperanza de que alguien se interese en publicar un libro de la calidad que se merecen estos grandes fotógrafos sin cuyo aporte no existiría la historia gráfica del Perú desde la segunda mitad del siglo XIX hasta las primeras del siglo XX. 


\section{Referencias citadas}

EL COMERCIO, 1842 - Daguerrotipo. El Comercio, 8 de julio, $\mathbf{n}^{\circ}$ 928: 4; Lima.

EL COMERCIO, 1846 - Furnier, Daguerrotipógrafo de París. El Comercio, 27 de marzo, $\mathbf{n}^{\circ} \mathbf{2 0 3 6}$ : 4; Lima.

EL COMERCIO, 1859 - Retratos de E. Garreaud y Cía. El Comercio, 7 de junio, nº 6095: 1.

EL MERCURIO, 1863 - Aviso. El Mercurio, 4 de mayo: última pagina.

FRIZOT, M., 1998 - A New History of Photography, 776 p.; France: Éditions Adam Biro, Könemann.

LAUREL, A. G., 1861 - Anuario Nacional 1862. Lima: El Comercio.

MACERA DALL'ORSO. P., 1976 - La imagen francesa del Perú (siglos XVI-XIX), 174 p.; Lima: Instituto Nacional de Cultura.

MAJLUF, N. \& WUFFARDEN, L. E., 2001 - La recuperación de la memoria: el primer siglo de la fotografía, Perú: 1842-1942. Vol. 2: Documentos para la historia de la fotografía peruana, s. p.; Lima: Fundación Telefónica y Museo de Arte de Lima.

MCELROY, D. K., 1977 - The History of Photography of Peru in the Nineteenth Century, 18391876. The University of New Mexico, Ph.D., Fine Arts.

MCELROY, K. E., 2000 - Courret and the Courret Archive in Lima, Peru. In: History of Photography Volume 24, Number 2: 121-126.

PEÑAHERRERA, L., 1983 - Un documento histórico: la fotografía en el Perú (1895-1919), 235 p.; Lima: Pontificia Universidad Católica del Perú. Programa de Letras y Ciencias Humanas.

THORNDIKE, G., 1979 - Autorretrato, Perú 1850-1900, 164 p.; Lima: Promoinvest compañía de inversiones S.A. 